"This is the peer reviewed version of the following article: Opara, Elizabeth I (2019) Culinary herbs and spices : what can human studies tell us about their role in the prevention of chronic non-communicable diseases? Journal of the Science of Food and Agriculture, 99(10), pp. 4511-4517., which has been published in final form at https://doi.org/10.1002/jsfa.9658. This article may be used for non-commercial purposes in accordance with Wiley Terms and Conditions for Use of Self-Archived Versions 


\section{Culinary herbs and spices: what can human studies tell us about their role in the prevention}

of chronic non-communicable diseases?

Culinary herbs and spices and prevention of chronic non-communicable diseases

Elizabeth I. Opara

School of Life Sciences, Pharmacy and Chemistry, Faculty of Science, Engineering and Computing, Kingston University, Penrhyn Road, Kingston upon Thames, KT1 2EE, UK Email: e.opara@kingston.ac.uk

\section{Abstract}

Culinary herbs and spices (CHS) are known primarily as flavour enhancers, and it is now well established that they possess bioactive properties that indicate that these foods may have a role to play in the prevention of non-communicable chronic diseases (CNCDs). Human studies are now beginning to provide insights into the significance of the potential health benefits of CHS in a dietary context, particularly concerning their antioxidant and anti-inflammatory properties and their impact on glucose homeostasis, appetite and the consumption of low/reduced fat, salt and sugar foods. However, these studies have also identified a number of factors that are very pertinent to furthering understanding of how CHS can be used for the maintenance of health and the prevention of CNCDs. The challenge for the next phase of studies will be how to incorporate, successfully, these factors into study methodology for investigating the preventative benefits of these foods.

Keywords: culinary herbs and spices, bioactive properties, chronic non-communicable diseases, human studies 


\section{Introduction}

There is a significant body of work concerning the use of culinary herbs and spices (CHS) beyond their use as flavour enhancing foods. History provides evidence of their use for medicinal purposes in Ancient China, Greece, India and Rome for the treatment of cancer, jaundice, gastro-intestinal infections, mouth ulcers, asthma, and chest problems, as well as to boost memory and cognitive performance ${ }^{(1)}$. More recently, research has focussed on bioactive properties that indicate that these foods might have a role to play in the prevention of chronic non-communicable diseases (CNCDs) including cardiovascular disease, cancer and type 2 diabetes $(T 2 D)^{(2-5)}$. These bioactive properties, which include their antioxidant, anti-inflammatory and anti-cancer activities, and their effect on glucose and lipid metabolism and food intake, are known to be conferred on them by their phytochemical constituents particularly, but not limited to, those that are polyphenolic ${ }^{(6-9)}$.

What can this growing body of evidence concerning the bioactive properties of CHS tell us about their significance in relation to CNCDs prevention, specifically in a dietary context? Work carried out in vitro provides valuable insights into their mechanisms of action. However, despite some addressing how they are consumed, the amounts used and processes that impact on them post-consumption, such studies are limited as they are unable to take into consideration other factors that are key to CHS bioactivity in vivo ${ }^{(6,10)}$. Animal studies can begin to shed light on their action in vivo but are small in number and are limited due to species differences ${ }^{(5,11)}$. To answer the question above it is necessary to consider in vivo studies done using healthy humans, or those at risk of developing CNCDs. However, it is important that such studies are focussed on the benefits of whole $\mathrm{CHS}$, rather than their phytochemical constituents, and have considered intake levels that are palatable and reflect habitual use in food preparation and consumption.

\section{Culinary herbs and spices: their antioxidant and anti-inflammatory activities in vivo}

The antioxidant and anti-inflammatory properties of $\mathrm{CHS}$ are well established in vitro. However, the findings from human studies are mixed (Table 1). One CHS study by Percival et al., ${ }^{(12)}$ investigated 
their bioavailability in healthy humans by measuring antioxidant capacity and also their effect, ex vivo, on DNA damage and markers of inflammation post consumption of individual CHS (black pepper, cinnamon, clove, cumin, ginger, oregano, paprika, rosemary, turmeric and sage) in capsule form for 7 days. The amounts per capsule were based on those typically consumed. Although, in an acknowledgement of the challenges of obtaining accurate intake data, to determine typical consumption it was assumed that all foods consumed per day were seasoned. Thus, the authors noted that the amounts used were likely over-estimations. Interestingly, no increases in antioxidant capacity were detected in the subjects' sera which was attributed to the marked intra/inter individual variability between the subjects' samples. These results suggest that the use of antioxidant capacity as a biomarker of antioxidant effect, in vivo, needs to be treated with caution. In contrast, a number of the CHS namely paprika, rosemary, ginger, heat-treated turmeric, sage and cumin protected peripheral blood mononuclear cells taken from the volunteers against DNA damage ex vivo. Expression ex vivo of cytokine markers of inflammation, namely TNF- $\alpha$, IL-1 $\alpha$ and IL-6 mRNA was also decreased. However, those with the highest antioxidant capacities (clove, rosemary and turmeric) did not significantly decrease the expression of all three inflammatory markers (only TNF- $\alpha$ was affected). It was ginger, the CHS with one of the lowest antioxidant capacities, which stood out as the only CHS to decrease the expression of all three markers. Thus, suggesting that the anti-inflammatory activity of at least some CHS may be independent of their ability to act as antioxidants. This study provides evidence of the potential benefit of CHS on DNA damage and inflammation, which both play a significant role in the aetiology of CNCDS. One may argue that the fact that the responses are ex vivo is a limitation. However, being able to demonstrate these significant responses in vivo would be extremely difficult, if not unlikely, as the subjects used were healthy and thus not in an inflammatory state of a magnitude similar to that simulated ex vivo. A study in which rosemary extract $(77.7 \mathrm{mg})$ given in capsule form for 21 days appears to add credence to this view ${ }^{(13)}$. It used healthy volunteers who were either smokers or had a family history of symptomatic atherosclerosis, and thus could be considered to be at risk. Although non-significant decreases in serum TNF- $\alpha$ and C-reactive protein 
(CRP) were observed, the levels of plasminogen activator inhibitor type 1 (PAI-1), whose expression has been shown to be stimulated by TNF- $\alpha$ and IL- $6^{(14)}$, decreased significantly along with the rate of arterial endothelial dysfunction (ED). It may be that the non-significant decreases in the inflammatory markers were sufficient to result in this change in PAI-1. Although both studies provide some evidence of the protective effect of individual CHS, they also highlight the difficulties of demonstrating in vitro bioactive properties of $\mathrm{CHS}$ in vivo.

In a study by Li et al., ${ }^{(15)}$, CHS were not given individually but as part of a non-herb food, namely hamburger meat. They investigated the effects of a high antioxidant CHS blend, containing black pepper, clove, cinnamon, garlic, ginger, oregano, paprika and rosemary, combined with the hamburger meat on levels of malondialdehyde in healthy human volunteers. Malondialdehyde is a product of lipid oxidation which can form DNA adducts, and thus may have a role to play in atherogenesis and carcinogenesis. In designing the study to include CHS seasoned hamburger meat the authors recognised that CHS are normally consumed with other foods. Compared to the study discussed above ${ }^{(12)}$, the amount consumed in one take was high (11.3g) however, palatability of the spiced hamburger was not significantly affected. Consumption of the spiced hamburger resulted in a trend to decrease plasma malondialdehyde over a six hour period following consumption. In addition, urinary malondialdehyde levels decreased significantly following the consumption of the spiced burger. The effect of a similar CHS blend (modified to ensure it was appropriate for the foods to which it was combined - dessert biscuit, coconut chicken and cheese bread) on post-prandial changes to plasma antioxidant capacity in healthy subjects who were overweight has also been investigated ${ }^{(16)}$. The total amount used was high at $14 \mathrm{~g}$ but again palatability was not affected significantly. Unlike the findings of Percival et al., ${ }^{(12)}$, the study reported increases in plasma antioxidant capacity suggesting that as with ${ }^{(15)}$ the blend worked to improve antioxidant status and ultimately confer protection via this action. However, the increases were not consistent and appeared to be dependent on the hydrophilicity and lipophilicity of the antioxidant compounds, and the type of assay used. Some antioxidant assays are affected by any compound that possesses reducing power which raises 
questions about their usefulness with regards to the determination of antioxidant activity in vivo ${ }^{(17,18)}$. Overall, these CHS blend studies are of significance as they provide more evidence of the protective effect of CHS in dietary contexts, albeit in controlled settings. However, to provide further insights concerning benefit, and how they confer it, the effect of these and other CHS blends combined with non-herb foods/meals for periods that reflect habitual consumption needs to be investigated.

\section{Culinary herbs and spices: their effect of on glucose homeostasis:}

Another major focus of the potential benefits of $\mathrm{CHS}$ is their effect on glucose homeostasis as some have been shown to possess insulin-like activities via their polyphenolic constituents in vitro ${ }^{(5)}$. These properties have led to a plethora of studies in which the therapeutic potential of CHS in the management of T2D has been assessed ${ }^{(5)}$. These studies have formed the basis for investigating their preventative potential with regards the development of T2D (Table 2). For example, the impact of cinnamon on post-prandial glucose in healthy and pre-diabetic subjects has been the focus of much attention. In their study on the effects of cinnamon on glucose tolerance, Solomon and Balnnin (2007) ${ }^{(19)}$ reported that following the ingestion of capsulated cinnamon $(5 \mathrm{~g})$ by lean healthy male volunteers, their total plasma glucose response to oral glucose was decreased. In addition, their insulin sensitivity was improved. However, the authors acknowledged that the amount given far exceeded what is typically consumed (although the subjects did not report any problems with ingestion). Markey et al., (2011) ${ }^{(20)}$ investigated the effect of a smaller amount of powdered cinnamon spice in capsules (3g in total) taken directly before and after the consumption of a high fat meal, and reported no effect on gastric emptying, glucose homeostasis, blood lipid levels, lipid peroxidation and vascular function, specifically arterial stiffness. The relatively low amount of cinnamon used, an amount that is closer to what is typically consumed, based on the estimations provided by ${ }^{(12)}$, could be identified as the major contributor to the lack of effect. However, the authors identified other factors may have influenced the results including: the subjects not being in a hyperglycaemic nor a hyperlipidaemic state; and the meal having a high, but not sufficient, fat content to give rise to changes in vascular function that were 
significant. How influential these factors are is unclear as the subjects were healthy and they consumed the high fat meal once in a 15 minute period. However, the authors' suggestions do highlight the challenge of simulating real world food consumption in a controlled environment.

In pre-diabetic overweight and obese subjects, cinnamon in capsule form (250mg twice a day for 12 weeks, which based on data from ${ }^{(11)}$ is approximately half of what is typically consumed) was shown to decrease fasting blood glucose (FBG). However, insulin levels were unchanged ${ }^{(21)}$. The decrease in fasting glucose was associated with changes in some but not all of the markers of oxidative stress measured which highlights again the issue of inconsistency concerning measures of antioxidant effect. However, there was a significant positive correlation between changes in FBG and malondialdehyde. In fact, the antioxidant effect essentially mirrored that of FBG - a relationship which might be interpreted as providing supporting evidence of impaired FBG causing oxidative stress in obesity (22) which is diminished by cinnamon. Similar findings, concerning the effect of cinnamon on FBG in prediabetic overweight and obese subjects, have been reported in a more recent study ${ }^{(23)}$.

Bearing in mind the importance of the dietary context, it is necessary to establish the impact the CHS when consumed with a meal on blood glucose. A number of studies show that $\mathrm{CHS}$, specifically cinnamon, turmeric and CHS blends, all consumed as part of a meal or beverage, lower post-prandial blood glucose ${ }^{(24-26)}$. The results of some of these studies indicate that dose may be an important factor when it comes to efficacy. For example, $6 \mathrm{~g}$ of cinnamon consumed with a meal (rice pudding) was reported to decrease post-prandial blood glucose. In contrast, 1, 3, and 4g of cinnamon consumed with a similar meal were reported as having no effect when consumed with a meal ${ }^{(24,27,28)}$. However, the 1 and $3 g$ doses resulted in a decrease in insulin (the decrease was significant for the higher dose) Furthermore, the $3 \mathrm{~g}$ dose resulted in a significant increase in the levels of glucagon-like peptide 1 (GLP-1), a gastrointestinal peptide hormone known to delay gastric emptying and stimulate glucose dependent insulin secretion ${ }^{(29,30)}$. Other studies point to the use of CHS in combination, and not dose, as a requirement for efficacy. Skulas-Ray et al., ${ }^{(15)}$ reported that post-consumption of foods spiced 
with black pepper, cinnamon, cloves, ginger, oregano, paprika, rosemary and/or turmeric significantly decreased post-prandial insulin and triglyceride responses. The meals had no effect on post-prandial glucose but the small glycaemic response to the un-spiced control meal is argued to have accounted for this effect. Furthermore, Hadar et al., ${ }^{(26)}$ reported that a polyphenol rich curry (the Polypspice curry) prepared using a CHS blend (of 6 and $12 \mathrm{~g}$ in total) and vegetables had a significant dosedependent effect in decreasing blood glucose in healthy subjects. This effect is thought to involve GLP1 as a subsequent study using the Polyspice curry reported that this hormone was increased in a dosedependent manner ${ }^{(31)}$.

The single CHS studies have their place in helping to establish whether or not CHS can confer benefit but it is the combined CHS studies, specifically, that are extremely informative as they recognised the need to investigate the effects of CHS in a 'real life dietary context'. They also went one step further as they determined the composition and doses of the blend based on typical consumption. Furthermore, they highlight that the form and composition of the CHS blends and, as with some of the single CHS studies ${ }^{(19)}$, the composition of the test meals are factors that cannot be ignored when investigating efficacy. These factors, therefore, need to be taken into consideration in future studies, possibly by using a variety of test meals as stated earlier. Finally, for both the single and combined CHS studies in which CHS were consumed as part of a meal, the choice of subjects may also be an influencing factor on the impact of CHS on glucose homeostasis. Subjects were either overweight ${ }^{(16)}$, normal ${ }^{(23,25)}$ or normal to overweight ${ }^{(25-27)}$. In light of literature that points to body composition influencing the efficacy of plant derived foods, and the large inter-individual variations in glycaemic response reported for ${ }^{(26)}$, it is tempting to speculate that the subjects who were overweight were in a state of insulin resistance, which resulted in greater responses.

Overall, human studies indicate that $\mathrm{CHS}$, particularly those involving the consumption of $\mathrm{CHS}$ blends, in amounts typically used as part of a meal, are able to influence glucose homeostasis possibly via actions on glucose regulating hormones, insulin and GLP-1. However, the use of such blends in long- 
term studies is needed to determine the true significance of such effects in relation to the development of T2D.

\section{Culinary herbs and spices: their effect on appetite}

Another activity possessed by CHS which could confer protection is their effect on appetite, and food intake, for the purpose of weight maintenance following weight loss ${ }^{(32)}$ (Table 2). The bases for this work are their sensory properties and their impact on food choice and energy intake. It has been theorised that such foods may give rise to cephalic phase responses involving the secretion of gut hormones, including glucagon-like peptide 1 (GLP-1) and ghrelin, which have been shown to alter appetite and metabolism via their satiety enhancing/anorexigenic and appetite stimulating/orexigenic effects respectively ${ }^{(33,34)}$. Other purported mechanisms include their thermogenic effects via sensory stimulation and the action of their constituent polyphenols and flavour compounds on digestive processes (32). Black pepper, cinnamon, ginger, horseradish and saffron have all been investigated for their appetitive effects based on one or more of the mechanisms listed above. However, the findings are mixed and thus far from definitive $(25,32,35,36)$.

Another CHS, which has been the focus of this area of research, is red chilli pepper due to its constituent capsaicin. Capsaicin is responsible primarily for the pungent aroma and taste of this CHS, and, via the activation of the central nervous system located 'capsaicin receptor', is reported to increase lipid oxidation and decrease adipose tissue ${ }^{(9,37-40)}$. A systematic review of human studies ${ }^{(41)}$ in which red chilli pepper is consumed on its own, in capsule form, or combined with non-herb foods/meals (including soups and high carbohydrate/fat meals) identified studies that reported increases in energy expenditure (EE), decreases in appetite and/or energy intake. A small number of these studies suggested that the increase in EE equated to approximately between 50 - $100 \mathrm{kcal} /$ day; the upper range for a $100 \mathrm{~kg}$ person ${ }^{(42,43)}$. Whether these estimated changes are of significance in terms of weight loss is not clear but one study concluded that a $50 \mathrm{kcal} /$ day increase would produce levels of clinically significant weight loss over a 1-2 year period ${ }^{(43)}$. 
Form and amount are influential with respect to outcome. Regarding the former, red chilli pepper consumed orally generally resulted in greater increases in fat oxidation and energy expenditure, and greater decreases in energy intake, than when taken in capsule form. Thus, suggesting that oral stimulation enhances the effect of this $\mathrm{CHS}{ }^{(44)}$. Effective amounts also vary and reflect the impact of subjects who were users or non-users and the variations in global/cultural differences in the amounts that are consumed ${ }^{(41,45)}$. Such variations have raised questions as to whether recommendations to increase the intake of red chilli pepper can realistically be sustained. This is a salient point, especially for those who consume very little if any CHS and are likely to find red chilli pepper extremely pungent and thus unpalatable (a factor that can in itself suppress appetite) ${ }^{(41)}$.

More recent work on the CHS blend containing Polyspice curry provides further support for the role of CHS in modulating appetite. At the same amounts shown to decrease post-prandial glucose and increase GLP-1 ${ }^{(26,31)}$, the meal is reported to significantly suppress hunger and the desire to eat compared to the unseasoned control ${ }^{(46)}$. However, this suppression was not dose-dependent and had no effect on ghrelin. Although promising, currently, this result can do no more than suggest that the Polyspice curry might be of use in the maintenance of weight following weight loss. For more definitive data, studies of the effect of meals seasoned with $\mathrm{CHS}$ in the context of habitual food intake are needed $^{(46)}$.

\section{Culinary herbs and spices: the conferring of protection via their role as flavour enhancers for low fat, low sugar and low salt foods}

Studies on the potential benefit of CHS via their role as flavour enhancers involve a very different approach to work focussed on their bioactive properties. High intakes of fat (especially saturated fat), salt and/or sugar are associated with increased risk of developing CNCDs ${ }^{(47-51)}$. Thus, strategies to help consumers make healthy choices with regards their diet include the use of low/reduced fat, salt 
and sugar foods. However, fat, sugar and salt are major flavour contributors, and thus drivers of acceptance and ultimately consumption.

Culinary herbs and spices are used in the preparation of food primarily to enhance their flavour, and they are of little to no calorific value. Based on these attributes, a small but growing amount of research ${ }^{(52-60)}$ suggests that a variety of CHS may be effective in increasing the overall liking of reduced/low fat, salt and sugar foods. This work also suggests that CHS may be successful in reducing the addition of salt to low salt foods such as vegetables. Considering their bioactive properties, the successful use of CHS in such a capacity could have a dual benefit. However, despite the suggestion of efficacy, collectively these studies have identified a number of factors that need to be considered before such a strategy can be implemented successfully. These factors include:

- The flavour profile and intensity of the test foods/meals used

- The nutrient/phytochemical composition of the test foods/meals used

- Familiarity with the CHS

- Cultural influences on the choice and amount of CHS used

- The impact of the amount and type of CHS used on palatability

- The form/preparation of the test meal - freshly prepared or canned or frozen and re-heated, and the inclusion of non-CHS ingredients

- The duration of exposure to foods with CHS added

- The influence of CHS when part of a broader strategy to reduce fat, salt and sugar intake

Interestingly some of these factors have also been highlighted above in the discussion above concerning the bioactive properties of CHS which indicates that they (the factors) are very pertinent to understanding more fully how $\mathrm{CHS}$ can be used effectively in maintaining health and preventing CNCDs. 


\section{Conclusion}

Studies carried out in vitro on CHS have their place concerning the elucidation of their mechanisms of action, and single studies have proven to be useful in identifying benefits of individual CHS in humans. However, in a dietary context, the key to establishing definitively what their significance is lies in studies in which their habitual use, specifically how they are used and consumed typically, is taken into consideration. Human studies using such an approach have provided some compelling evidence that CHS are of benefit to the maintenance of health at amounts that are typically consumed. These studies have, via their findings, also highlighted the need to address a number of factors. These include nutrient and phytochemical composition of the test meal, the type of subjects in relation to risk, levels of habitual consumption, palatability and biomarkers of effect. These factors are likely to be integral to furthering understanding of the significance of the benefits demonstrated thus far. The challenge for the next phase of investigations, into the preventative benefits of these foods, will be to incorporate, successfully, these factors into study methodology.

\section{References}

(1) Tapsell LC, Hemphill I, Cobiac L, Patch CS, Sullivan DR, Fenech M, et al. Health benefits of herbs and spices: the past, the present, the future. Med J Aust 2006 August 21;185(4 Suppl):4.

(2) Tapsell LC, Hemphill I, Cobiac L, Patch CS, Sullivan DR, Fenech M, et al. Health benefits of herbs and spices: the past, the present, the future. Med J Aust 2006 August 21;185(4 Suppl):4.

(3) Kaefer CM, Milner JA. The role of herbs and spices in cancer prevention. J Nutr Biochem 2008 June 01;19(6):347-361.

(4) Jungbauer A, Medjakovic S. Anti-inflammatory properties of culinary herbs and spices that ameliorate the effects of metabolic syndrome. Maturitas 2012 March 01;71(3):227-239.

(5) Bi X, Lim J, Henry CJ. Spices in the management of diabetes mellitus. Food Chem 2017 February 15;217:281-293. 
(6) Opara El, Chohan M. Culinary herbs and spices: their bioactive properties, the contribution of polyphenols and the challenges in deducing their true health benefits. Int J Mol Sci 2014 October 22;15(10):19183-19202.

(7) Chohan M, Naughton DP, Jones L, Opara El. An investigation of the relationship between the antiinflammatory activity, polyphenolic content, and antioxidant activities of cooked and in vitro digested culinary herbs. Oxid Med Cell Longev 2012;2012:627843.

(8) Jaksevicius A, Carew M, Mistry C, Modjtahedi H, Opara El. Inhibitory Effects of Culinary Herbs and Spices on the Growth of HCA-7 Colorectal Cancer Cells and Their COX-2 Expression. Nutrients 2017 September 21;9(10):10.3390/nu9101051.

(9) Whiting S, Derbyshire EJ, Tiwari B. Could capsaicinoids help to support weight management? A systematic review and meta-analysis of energy intake data. Appetite 2014 February 01;73:183-188.

(10) D'Archivio M, Filesi C, Vari R, Scazzocchio B, Masella R. Bioavailability of the polyphenols: status and controversies. Int J Mol Sci 2010 March 31;11(4):1321-1342.

(11) Qin B, Nagasaki M, Ren M, Bajotto G, Oshida Y, Sato Y. Cinnamon extract (traditional herb) potentiates in vivo insulin-regulated glucose utilization via enhancing insulin signaling in rats. Diabetes Res Clin Pract 2003 December 01;62(3):139-148.

(12) Percival SS, Vanden Heuvel JP, Nieves CJ, Montero C, Migliaccio AJ, Meadors J. Bioavailability of herbs and spices in humans as determined by ex vivo inflammatory suppression and DNA strand breaks. J Am Coll Nutr 2012 August 01;31(4):288-294.

(13) Sinkovic A, Suran D, Lokar L, Fliser E, Skerget M, Novak Z, et al. Rosemary extracts improve flowmediated dilatation of the brachial artery and plasma PAI-1 activity in healthy young volunteers. Phytother Res 2011 March 01;25(3):402-407.

(14) Cesari M, Pahor M, Incalzi RA. Plasminogen activator inhibitor-1 (PAI-1): a key factor linking fibrinolysis and age-related subclinical and clinical conditions. Cardiovasc Ther 2010 October 01;28(5):72.

(15) Li Z, Henning SM, Zhang Y, Zerlin A, Li L, Gao K, et al. Antioxidant-rich spice added to hamburger meat during cooking results in reduced meat, plasma, and urine malondialdehyde concentrations. Am J Clin Nutr 2010 May 01;91(5):1180-1184.

(16) Skulas-Ray AC, Kris-Etherton PM, Teeter DL, Chen CY, Vanden Heuvel JP, West SG. A high antioxidant spice blend attenuates postprandial insulin and triglyceride responses and increases some plasma measures of antioxidant activity in healthy, overweight men. J Nutr 2011 August 01;141(8):1451-1457.

(17) Huang D, Ou B, Prior RL. The chemistry behind antioxidant capacity assays. J Agric Food Chem 2005 March 23;53(6):1841-1856.

(18) Prior RL, Wu X, Schaich K. Standardized methods for the determination of antioxidant capacity and phenolics in foods and dietary supplements. J Agric Food Chem 2005 May 18;53(10):4290-4302.

(19) Solomon TPJ, Blannin AK. Effects of short-term cinnamon ingestion on in vivo glucose tolerance. Diabetes, Obesity and Metabolism 2007;9(6):895-901. 
(20) Markey O, McClean CM, Medlow P, Davison GW, Trinick TR, Duly E, et al. Effect of cinnamon on gastric emptying, arterial stiffness, postprandial lipemia, glycemia, and appetite responses to highfat breakfast. Cardiovasc Diabetol 2011 September 07;10:78.

(21) Roussel AM, Hininger I, Benaraba R, Ziegenfuss TN, Anderson RA. Antioxidant effects of a cinnamon extract in people with impaired fasting glucose that are overweight or obese. J Am Coll Nutr 2009 February 01;28(1):16-21.

(22) Osawa T, Kato Y. Protective role of antioxidative food factors in oxidative stress caused by hyperglycemia. Ann N Y Acad Sci 2005 June 01;1043:440-451.

(23) Anderson RA, Zhan Z, Luo R, Guo X, Guo Q, Zhou J, et al. Cinnamon extract lowers glucose, insulin and cholesterol in people with elevated serum glucose. J Tradit Complement Med 2015 April 18;6(4):332-336.

(24) Hlebowicz J, Darwiche G, Bjorgell O, Almer LO. Effect of cinnamon on postprandial blood glucose, gastric emptying, and satiety in healthy subjects. Am J Clin Nutr 2007 June 01;85(6):15521556.

(25) Zanzer YC, Plaza M, Dougkas A, Turner C, Björck I, Östman E. Polyphenol-rich spice-based beverages modulated postprandial early glycaemia, appetite and PYY after breakfast challenge in healthy subjects: A randomized, single blind, crossover study. Journal of Functional Foods 2017;35:574-583.

(26) Haldar S, Chia SC, Lee SH, Lim J, Leow MK, Chan ECY, et al. Polyphenol-rich curry made with mixed spices and vegetables benefits glucose homeostasis in Chinese males (Polyspice Study): a dose-response randomized controlled crossover trial. Eur J Nutr 2017 December 13.

(27) Hlebowicz J, Hlebowicz A, Lindstedt S, Bjorgell O, Hoglund P, Holst JJ, et al. Effects of 1 and $3 \mathrm{~g}$ cinnamon on gastric emptying, satiety, and postprandial blood glucose, insulin, glucose-dependent insulinotropic polypeptide, glucagon-like peptide 1, and ghrelin concentrations in healthy subjects. Am J Clin Nutr 2009 March 01;89(3):815-821.

(28) Mettler S, Schwarz I, Colombani PC. Additive postprandial blood glucose-attenuating and satiety-enhancing effect of cinnamon and acetic acid. Nutr Res 2009 October 01;29(10):723-727.

(29) Kieffer TJ, Habener JF. The glucagon-like peptides. Endocr Rev 1999 December 01;20(6):876913.

(30) Nauck MA, Niedereichholz U, Ettler R, Holst JJ, Orskov C, Ritzel R, et al. Glucagon-like peptide 1 inhibition of gastric emptying outweighs its insulinotropic effects in healthy humans. Am J Physiol 1997 November 01;273(5 Pt 1):981.

(31) Haldar S, Chia SC, Henry CJ. Polyphenol-rich curry made with mixed spices and vegetables increases postprandial plasma GLP-1 concentration in a dose-dependent manner. Eur J Clin Nutr 2018 February 01;72(2):297-300.

(32) Mattes RD. Spices and energy balance. Physiol Behav 2012 November 05;107(4):584-590.

(33) Woods SC. The control of food intake: behavioral versus molecular perspectives. Cell Metab 2009 June 01;9(6):489-498. 
(34) Heath RB, Jones R, Frayn KN, Robertson MD. Vagal stimulation exaggerates the inhibitory ghrelin response to oral fat in humans. J Endocrinol 2004 February 01;180(2):273-281.

(35) Gregersen NT, Belza A, Jensen MG, Ritz C, Bitz C, Hels O, et al. Acute effects of mustard, horseradish, black pepper and ginger on energy expenditure, appetite, ad libitum energy intake and energy balance in human subjects. Br J Nutr 2013 February 14;109(3):556-563.

(36) Zanzer YC, Plaza M, Dougkas A, Turner C, Ostman E. Black pepper-based beverage induced appetite-suppressing effects without altering postprandial glycaemia, gut and thyroid hormones or gastrointestinal well-being: a randomized crossover study in healthy subjects. Food Funct 2018 May 23;9(5):2774-2786.

(37) Whiting S, Derbyshire E, Tiwari BK. Capsaicinoids and capsinoids. A potential role for weight management? A systematic review of the evidence. Appetite 2012 October 01;59(2):341-348.

(38) Yang F, Zheng J. Understand spiciness: mechanism of TRPV1 channel activation by capsaicin. Protein Cell 2017 March 01;8(3):169-177.

(39) Kawada T, Hagihara K, Iwai K. Effects of capsaicin on lipid metabolism in rats fed a high fat diet. J Nutr 1986 July 01;116(7):1272-1278.

(40) Kawada T, Sakabe S, Watanabe T, Yamamoto M, Iwai K. Some pungent principles of spices cause the adrenal medulla to secrete catecholamine in anesthetized rats. Proc Soc Exp Biol Med 1988 June 01;188(2):229-233.

(41) Ludy MJ, Moore GE, Mattes RD. The effects of capsaicin and capsiate on energy balance: critical review and meta-analyses of studies in humans. Chem Senses 2012 February 01;37(2):103-121.

(42) Galgani JE, Ravussin E. Effect of dihydrocapsiate on resting metabolic rate in humans. Am J Clin Nutr 2010 November 01;92(5):1089-1093.

(43) Snitker S, Fujishima Y, Shen H, Ott S, Pi-Sunyer X, Furuhata Y, et al. Effects of novel capsinoid treatment on fatness and energy metabolism in humans: possible pharmacogenetic implications. Am J Clin Nutr 2009 January 01;89(1):45-50.

(44) Westerterp-Plantenga MS, Smeets A, Lejeune MP. Sensory and gastrointestinal satiety effects of capsaicin on food intake. Int J Obes (Lond) 2005 June 01;29(6):682-688.

(45) Astrup A, Kristensen M, Gregersen NT, Belza A, Lorenzen JK, Due A, et al. Can bioactive foods affect obesity? Ann N Y Acad Sci 2010;1190(1):25-41.

(46) Haldar S, Lim J, Chia SC, Ponnalagu S, Henry CJ. Effects of Two Doses of Curry Prepared with Mixed Spices on Postprandial Ghrelin and Subjective Appetite Responses-A Randomized Controlled Crossover Trial. Foods 2018 March 26;7(4):10.3390/foods7040047.

(47) Manson JE, Colditz GA, Stampfer MJ, Willett WC, Rosner B, Monson RR, et al. A prospective study of obesity and risk of coronary heart disease in women. N Engl J Med 1990 March 29;322(13):882-889.

(48) Song YM, Sung J, Davey Smith G, Ebrahim S. Body mass index and ischemic and hemorrhagic stroke: a prospective study in Korean men. Stroke 2004 April 01;35(4):831-836. 
(49) Wiseman MJ. Nutrition and cancer: prevention and survival. Br J Nutr 2018 September 14:1-7.

(50) Te Morenga LA, Howatson AJ, Jones RM, Mann J. Dietary sugars and cardiometabolic risk: systematic review and meta-analyses of randomized controlled trials of the effects on blood pressure and lipids. Am J Clin Nutr 2014 July 01;100(1):65-79.

(51) Mozaffarian D, Fahimi S, Singh GM, Micha R, Khatibzadeh S, Engell RE, et al. Global sodium consumption and death from cardiovascular causes. N Engl J Med 2014 August 14;371(7):624-634.

(52) Mitchell M, Brunton NP, Wilkinson MG. The influence of salt taste threshold on acceptability and purchase intent of reformulated reduced sodium vegetable soups. Food Quality and Preference 2013;28(1):356-360.

(53) Peters JC, Polsky S, Stark R, Zhaoxing P, Hill JO. The influence of herbs and spices on overall liking of reduced fat food. Appetite 2014 August 01;79:183-188.

(54) Ghawi SK, Rowland I, Methven L. Enhancing consumer liking of low salt tomato soup over repeated exposure by herb and spice seasonings. Appetite 2014 October 01;81:20-29.

(55) Wang C, Lee Y, Lee SY. Consumer acceptance of model soup system with varying levels of herbs and salt. J Food Sci 2014 October 01;79(10):2098.

(56) Polsky S, Beck J, Stark RA, Pan Z, Hill JO, Peters JC. The influence of herbs, spices, and regular sausage and chicken consumption on liking of reduced fat breakfast and lunch items. J Food Sci 2014 October 01;79(10):2117.

(57) Anderson CA, Cobb LK, Miller ER, Woodward M, Hottenstein A, Chang AR, et al. Effects of a behavioral intervention that emphasizes spices and herbs on adherence to recommended sodium intake: results of the SPICE randomized clinical trial. Am J Clin Nutr 2015 September 01;102(3):671679.

(58) Li, Zhaoping, Krak, Michael, Zerlin, Alona, Brahe, Lena, Rheinwalg-Jones, Alexis, Thames, Gail, Zhang, Yanjun, Tseng, Chi-Hong, Herber, David. The Impact of Spices on Vegetable consumption: A Pilot Study. Food and Nutrition Sciences 2015;6:437-444.

(59) Peters JC, Marker R, Pan Z, Breen JA, Hill JO. The Influence of Adding Spices to Reduced Sugar Foods on Overall Liking. J Food Sci 2018 March 01;83(3):814-821.

(60) Feng Y, Albiol Tapia M, Okada K, Castaneda Lazo NB, Chapman-Novakofski K, Phillips C, et al. Consumer Acceptance Comparison Between Seasoned and Unseasoned Vegetables. Journal of Food Science 2018;83(2):446-453. 
Table 1: Amounts of culinary herbs and spices (CHS) associated with effects that may confer prevention against the development of chronic non-communicable diseases (CNCDs) - antioxidant and anti-inflammatory studies

\begin{tabular}{|c|c|c|c|c|}
\hline Culinary herbs and spices & Amount consumed & Form & $\begin{array}{l}\text { Bioactive properties/potential } \\
\text { benefit }\end{array}$ & Reference \\
\hline Clove & $0.3 \mathrm{~g} /$ day for 7 days & Capsule & $\begin{array}{l}\text { Decreased expression of } \\
\text { inflammatory markers ex vivo }\end{array}$ & 11 \\
\hline Cinnamon & $\begin{array}{l}250 \mathrm{mg} \text {, twice a day for } 12 \\
\text { weeks }\end{array}$ & Dried aqueous extract & $\begin{array}{l}\text { Improvement in plasma } \\
\text { oxidative stress markers FRAP } \\
\text { and plasma thiol; decrease in } \\
\text { plasma malondialdehyde (in } \\
\text { pre-diabetic, overweight or } \\
\text { obese subjects) }\end{array}$ & 21 \\
\hline Cumin & $2.8 \mathrm{~g} /$ day for 7 days & Capsule & $\begin{array}{l}\text { Protection against DNA strand } \\
\text { breaks ex vivo }\end{array}$ & 11 \\
\hline Ginger & $2.8 \mathrm{~g} /$ day for 7 days & capsule & $\begin{array}{l}\text { Protection against DNA strand } \\
\text { breaks and decreased } \\
\text { expression of inflammatory } \\
\text { markers ex vivo }\end{array}$ & 11 \\
\hline Paprika & $1.7 \mathrm{~g} /$ day for 7 days & Capsule & $\begin{array}{l}\text { Protection against DNA strand } \\
\text { breaks ex vivo }\end{array}$ & 11 \\
\hline \multirow[t]{2}{*}{ Rosemary } & $2.8 \mathrm{~g} /$ day for 7 days & Capsule & $\begin{array}{l}\text { Protection against DNA strand } \\
\text { breaks and decreased } \\
\text { expression of inflammatory } \\
\text { markers ex vivo }\end{array}$ & 11 \\
\hline & $77.7 \mathrm{mg}$ per day for 21 days & Extract in tablet form & $\begin{array}{l}\text { Decreased PAI- } 1 \text { activity and } \\
\text { improvement in endothelial } \\
\text { dysfunction }\end{array}$ & 12 \\
\hline
\end{tabular}




\begin{tabular}{|c|c|c|c|c|}
\hline Sage & $1.7 \mathrm{~g} /$ day for 7 days & Capsule & $\begin{array}{l}\text { Protection against DNA strand } \\
\text { breaks ex vivo }\end{array}$ & 11 \\
\hline Turmeric & $0.3 \mathrm{~g} /$ day for 7 days & Capsule and heat treated & $\begin{array}{l}\text { Protection against DNA strand } \\
\text { breaks and decreased } \\
\text { expression of inflammatory } \\
\text { markers ex vivo }\end{array}$ & 11 \\
\hline CHS blend & $\begin{array}{l}\text { Black pepper }-0.7 \mathrm{~g} \\
\text { Clove }-0.5 \mathrm{~g} \\
\text { Cinnamon }-0.5 \mathrm{~g} \\
\text { Garlic (powdered)- } 1.5 \mathrm{~g} \\
\text { Ginger }-1.2 \mathrm{~g} \\
\text { Oregano }-3.0 \mathrm{~g} \\
\text { Paprika }-3.4 \mathrm{~g} \\
\text { Rosemary }-0.5 \mathrm{~g}\end{array}$ & $\begin{array}{l}\text { Ground (with the exception of } \\
\text { garlic) blend used to season } \\
\text { hamburger meat ( } 250 \mathrm{~g} \text { raw } \\
\text { weight) }\end{array}$ & $\begin{array}{l}\text { Reduction in plasma and urine } \\
\text { malondialdehyde vs. control }\end{array}$ & 14 \\
\hline CHS blend & $\begin{array}{l}\text { Black pepper }-0.91 \mathrm{~g} \\
\text { Cloves }-0.61 \mathrm{~g} \\
\text { Cinnamon }-0.61 \mathrm{~g} \\
\text { Garlic }-1.81 \mathrm{~g} \\
\text { Ginger }-1.51 \mathrm{~g} \\
\text { Oregano }-2.26 \mathrm{~g} \\
\text { Paprika }-2.85 \mathrm{~g} \\
\text { Rosemary }-0.61 \mathrm{~g} \\
\text { Turmeric }-2.79 \mathrm{~g}\end{array}$ & $\begin{array}{l}\text { Part of a CHS blend used to } \\
\text { season dessert biscuits, coconut } \\
\text { chicken and/or cheese bread }\end{array}$ & $\begin{array}{l}\text { Increase in hydrophilic ORAC } \\
\text { levels in plasma in healthy, } \\
\text { overweight subjects }\end{array}$ & 15 \\
\hline
\end{tabular}

Unless otherwise stated, healthy, normal weight subjects were used. Abbreviations: ORAC - oxygen radical absorbance capacity; FRAP - ferric reducing antioxidant power

Table 2: Amounts of culinary herbs and spices (CHS) associated with effects that may confer prevention against the development of chronic non-communicable diseases (CNCDs) - post-prandial, fasting blood glucose and appetite studies 


\begin{tabular}{|c|c|c|c|c|}
\hline Culinary herbs and spices & Amount consumed & Form & $\begin{array}{l}\text { Bioactive properties/potential } \\
\text { benefit }\end{array}$ & Reference \\
\hline Black pepper & Approx. 4.4g & Black pepper flavored water & $\begin{array}{l}\text { Lowered hunger and desire to } \\
\text { eat; increased satiety and } \\
\text { fullness; no effect on post- } \\
\text { prandial glucose and insulin; no } \\
\text { effect on anorexigenic } \\
\text { hormones, PYY and GLP-1 }\end{array}$ & 36 \\
\hline CHS blend & $\begin{array}{l}\text { Black pepper }-0.91 \mathrm{~g} \\
\text { Cloves - } 0.61 \mathrm{~g} \\
\text { Cinnamon }-0.61 \mathrm{~g} \\
\text { Garlic }-1.81 \mathrm{~g} \\
\text { Ginger }-1.51 \mathrm{~g} \\
\text { Oregano- }-2.26 \mathrm{~g} \\
\text { Paprika }-2.85 \mathrm{~g} \\
\text { Rosemary }-0.61 \mathrm{~g} \\
\text { Turmeric- } 2.79 \mathrm{~g}\end{array}$ & $\begin{array}{l}\text { Part of a CHS blend used to } \\
\text { season dessert biscuits, coconut } \\
\text { chicken and/or cheese bread }\end{array}$ & $\begin{array}{l}\text { No change in post-prandial } \\
\text { glucose, decrease in post- } \\
\text { prandial insulin and triglyceride } \\
\text { response to meal in healthy, } \\
\text { overweight subjects }\end{array}$ & 15 \\
\hline CHS blend & $\begin{array}{l}\text { Cayenne pepper (powder) - } \\
0.5 \mathrm{~g} \text { and } 1 \mathrm{~g} \\
\text { Cinnamon (powder) }-0.25 \mathrm{~g} \\
\text { and } 0.5 \mathrm{~g} \\
\text { Clove (powder) }-0.25 \mathrm{~g} \text { and } \\
0.5 \mathrm{~g} \\
\text { Coriander seeds (powder) - } 1 \mathrm{~g} \\
\text { and } 2 \mathrm{~g} \\
\text { Cumin seeds (powder) } 1 \mathrm{~g} \text { and } \\
2 \mathrm{~g} \\
\text { Garlic (fresh) }-10 \mathrm{~g} \text { and } 20 \mathrm{~g} \\
\text { Ginger (fresh) }-10 \mathrm{~g} \text { and } 20 \mathrm{~g} \\
\text { Indian gooseberry 'amla' } \\
\text { powder - } 1 \mathrm{~g} \text { and } 2 \mathrm{~g} \\
\text { Turmeric (powder) }-2 \mathrm{~g} \text { and } 4 \mathrm{~g}\end{array}$ & $\begin{array}{l}\text { Curry (also included tomato } \\
\text { puree, onions and aubergine ) }\end{array}$ & $\begin{array}{l}\text { Dose-dependent decrease in } \\
\text { post-prandial glucose and GLP- } \\
\text { 1; decrease in appetite. }\end{array}$ & 26,31 \\
\hline Cinnamon & $5 g$ & Capsule & $\begin{array}{l}\text { Decrease in total plasma } \\
\text { glucose responses to oral }\end{array}$ & 19 \\
\hline
\end{tabular}


$250 \mathrm{mg}$, twice a day for 12

weeks

Dried aqueous extract

$250 \mathrm{mg}$, twice a day for 8 weeks

Spray dried aqueous extract

$6 g$

$3 g$

$60 \mathrm{ml}$ extract equivalent to $6 \mathrm{~g}$

of dry weight

Consumed with rice pudding

Consumed with rice pudding (300g)

Spice-based beverage insulin in pre-diabetic,

overweight or obese subjects

Decrease in fasting glucose and fasting insulin in pre-diabetic subjects

Post-prandial glucose and gastric emptying lowered glucose; decrease in postprandial insulin levels; increase

Lowered increment in early blood glucose compared to
Decrease in fasting blood glucose, no change in fasting

No change in post-prandial in GLP-1, no effect on appetite control

Preoccupation with food and meal or drink desire to eat decreased but

only for those who were

nonusers of red pepper

Increase in desire to eat sweet

foods, decrease in desire to eat hot foods, no effect on energy

or food intake 
No effect on desire to eat,

fullness, prospective food

intake or hunger

Increase/trend to increase in

GLP-1, trend towards a

decrease in ghrelin, no change

to PYY or satiety

Increase in energy expenditure

and carbohydrate and fat

oxidation

Approx. 0.4g-approx. $2 \mathrm{~g} \quad$ Capsule containing ground red chili pepper
Increase in satiety and

carbohydrate intake, decrease

in hunger and fat intake

Increase in fullness and satiety during negative energy balance and decrease in hunger during positive energy balance

Lowered increment in early blood glucose compared to control. Increased plasma PYY and lowered desire to eat and prospective food consumption (how much food the subject thought they could eat when asked).

Curry (also included tomato

$0.5 \mathrm{~g}$ and $1 \mathrm{~g}$

Cinnamon (powder) - $0.25 g$ puree, onions and aubergine

Dose-dependent decrease in post-prandial glucose and GLP-

1 ; decrease in appetite. 
Clove (powder) $-0.25 g$ and

$0.5 \mathrm{~g}$

Coriander seeds (powder) $-1 \mathrm{~g}$

and $2 \mathrm{~g}$

Cumin seeds (powder) $1 \mathrm{~g}$ and

$2 \mathrm{~g}$

Garlic (fresh) - 10g and 20g

Ginger (fresh) $-10 \mathrm{~g}$ and $20 \mathrm{~g}$

Indian gooseberry 'amla'

powder $-1 \mathrm{~g}$ and $2 \mathrm{~g}$

Turmeric (powder) $-2 \mathrm{~g}$ and $4 \mathrm{~g}$

Unless otherwise stated, healthy subjects were used. Abbreviations: GLP-1 - glucagon-like peptide 1; PYY - peptide tyrosine tyrosine 